\title{
Article \\ Experimental Evaluation of Dry Powder Inhalers During In- and Exhalation Using a Model of the Human Respiratory System (xPULM ${ }^{\mathrm{TM}}$ )
}

\author{
Richard Pasteka $^{1,2, *(\mathbb{D})}$, Lara Schöllbauer ${ }^{1}$, Joao Pedro Santos da Costa ${ }^{1}$ (D), Radim Kolar ${ }^{2}$ and Mathias Forjan $^{1}(\mathbb{D})$ \\ 1 University of Applied Sciences Technikum Wien Department Life Science Engineering, Höchstaedtplatz 6, \\ Vienna \\ 2 Brno University of Technology Department of Biomedical Engineering, Technicka 3058, Brno \\ * Correspondence: Richard Pasteka; richard.pasteka@technikum-wien.at
}

check for updates

Citation: Pasteka, R.; Schöllbauer, L.;

Costa, J.P.; Kolar R.; Forjan, M.

Experimental Evaluation of Dry Powder Inhalers During In- and Exhalation Using a Model of the Human Respiratory System (xPULM ${ }^{\mathrm{TM}}$ ). Preprints 2021, 1, 0. https://doi.org/

Received:

Accepted:

Published:

Publisher's Note: MDPI stays neutral with regard to jurisdictional claims in published maps and institutional affiliations.

\begin{abstract}
Dry powder inhalers are used by a large number of patients worldwide to treat respiratory diseases. The objective of this work is to experimentally investigate changes in aerosol particle diameter and particle number concentration of pharmaceutical aerosols generated by five dry powder inhalers under realistic inhalation and exhalation conditions. To simulate patients undergoing inhalation therapy, the active respiratory system model ( $\left.\mathrm{PPULM}^{\mathrm{TM}}\right)$ was used. A mechanical upper airway model was developed, manufactured and introduced as a part of the $\mathrm{XPULM}^{\mathrm{TM}}$ to represent the human upper respiratory tract with high fidelity. Integration of optical aerosol spectrometry technique into the setup allowed for evaluation of pharmaceutical aerosols. The results show that there is a significant difference $(\mathrm{p}<0.05)$ in mean particle diameter between inhaled and exhaled particles with the majority of the particles depositing in the lung, while particles with the size of $(>0.5 \mu \mathrm{m})$ are least influenced by deposition mechanisms. In the expiratory airstream, the mean particle number concentrations are 2.94\% (BreezHaler ${ }^{\circledR}$ ), 2.66\% (Diskus®), $10.24 \%$ (Ellipta $®$ ) $2.13 \%$ (HandiHaler ${ }^{\circledR}$ ) and $6.22 \%$ (Turbohaler ${ }^{\circledR}$ ), which are comparable to values published in previous studies.Furthermore, the mechanical upper airway model increases the resistance of the overall system and acts as a filter for larger particles $(>3 \mu \mathrm{m})$. In conclusion, the $\mathrm{XPULM}^{\mathrm{TM}}$ active respiratory system model is a viable option for studying interactions of pharmaceutical aerosols and the respiratory tract regarding applicable deposition mechanisms. The model strives to support the reduction of animal experimentation in aerosol research and provides an alternative to experiments with human subjects.
\end{abstract}

Keywords: dry powder inhaler resistance, inspiratory flow rate, inspiratory pressure, aerosol particle deposition, mechanical upper airway model, optical aerosol spectrometry, biomedical engineering

\section{Introduction}

According to the report on the global impact of respiratory disease published by the Forum of International Respiratory Societies from 2017 [1] approximately 65 million people globally suffer from mild to severe chronic obstructive pulmonary disease (COPD) and 334 million people suffer from asthma. In conjunction with acute lower respiratory tract infections, these diseases are among the most prevalent severe illnesses and causes of death. [1] Based on Eurostat statistics [2] from 2016, diseases of the respiratory system accounted for approximately 7,5\% of all deaths in the former EU-27. Targeted delivery of pharmaceuticals directly into the affected part of the respiratory region via inhalation drug therapy is crucial for managing cases of obstructive respiratory diseases [3].

Inhalation therapeutic devices can be categorised into four main types, including nebulisers, pressurised-metered dose inhalers (pMDI), soft mist inhalers (SMI) and dry powder inhalers (DPI) [3]. In terms of units sold in 2014, pMDIs and DPIs constitute the majority of devices for inhalation drug delivery [4]. For this reason, this article focuses purely on the evaluation of DPIs. In contrast to pMDIs, DPIs work with larger lactose particles carrying the active substance and are environmentally preferable due to the absence of hydrofluorcarbons [5]. Nevertheless, DPIs require a minimum peak flow during 
inhalation, created by the patient, to detach and propel the aerosol in direction of the lung regions. The lack of required synchronity between activation and inhalation of the DPI is reducing a potential source of misuse but does not cover for the problems caused by different activation mechanisms [6]. The optimum flow profile varies for the currently available DPIs and may lead to a suboptimal delivered dose for the patients [6]. Most recently developed DPIs only deliver a low dose of medication while the users have to be able to create a minimum inspiratory flow and have the cognitive ability to properly operate the DPI [7]. This is accompanied by the need for an adequate lung volume of the user, therefore excluding children below the age of 5 years as users [7]. Considering only a single peak inspiratory flow rate (PIFR) value as the main criterion for determining the capability of the patient to use an inhaler efficiently may be an insufficient criterion as the DPIs vary in their design and resistance to airflow [8]. While several available studies evaluating DPIs focus mainly on inspiratory flow rate [9-13] a more suitable criteria has proven to be ensuring a sufficient pressure drop of $\geq 1 \mathrm{kPa}$ across the device. Inhalation under these conditions leads to delivery of an adequate lung dose of the pharmaceutical [8]. Focusing on the pressure drop across the device could help prevent exclusion of patients from DPI usage due to insufficient or excessive peak inspiratory flow rate. Both have been shown to negatively impact pulmonary drug delivery $[9,14]$. Therefore, the pressure drop over the DPI has been taken as the main evaluation criterion for successful inhalation processes for this work.

In vitro pharmaceutical aerosol test systems often include either sample collection tubes or cascade impactors, such as the Andersen non-viable impactor, or the Next Generation Impactor to collect the particles for classification [15-17]. The results using such systems provide insights about the properties of the inhaled aerosol, such as the sizes of the inhaled particles and the deposition fraction, which can be used for comparison with radionuclide imaging studies[18] or to validate in-silico dosimetry models[19-21]. Cascade impactors consist of stages, each containing impaction plates which represent obstacles for an incoming airstream [22]. These plates create an abrupt bend in the airstream causing the particles, whose inertia exceeds a cut off size, to deposit [23]. Due to the operating principle of cascade impactors and sample collection tubes, evaluation of aerosol during consecutive inhalation and exhalation is not feasible [24]. The aerosol particles deposit on the impaction plates during inhalation and are consequently not present in the exhalatory airstream . For this reason, optical aerosol spectrometry was utilised in this work allowing for evaluation of particles within both inhalation and exhalation airstream.

Pulmonary drug delivery is based on the primary mechanisms of aerosol deposition, which are defined as inertial impaction, gravitational sedimentation, Brownian diffusion, turbulent deposition, electrostatic precipitation, and interception [25]. The effect of deposition mechanisms on aerosol particles depends on the particle characteristics such as particle size, overall size distribution, shape, composition, surface characteristics and charge [26]. Moreover, the processes resulting from molecular transfer between particles and their respective surrounding gas are nucleation, condensation, evaporation hygroscopicity and coagulation [27]. Inhalation drug therapy aims at targeted delivery of pharmaceuticals into the lung. The inhaled particles must overcome filtration mechanisms in the upper airways causing them to deposit within this region [28]. The deposition mechanism occurring mainly in the upper airways is inertial impaction affecting mostly large particles $(>2-5 \mu \mathrm{m})$ with a strong dependency on the airflow rate. The deposition in this region of the respiratory tract results from direction changes of flow when the particles deviate from the streamline and collide with the airway walls. The probability of such deviation can be described by the Stoke's number where particle diameter, carrier gas viscosity and airway diameter are used to calculate the probability of deposition.[29] In the respiratory tract, gravitational sedimentation of particles in the size range of $(>1-8 \mu \mathrm{m})$, refers to the settling of particles under the influence of gravity. Brownian diffusion results from random motion and the collision of the particles with the carrier gas molecules. The effect of mutual repulsion due to electric charges concerning the inhaled particles is defined as electrostatic 
precipitation. The described mechanisms arise mostly in the upper and conducting airway region of the respiratory tract, whereas diffusion and electrostatic precipitation is also taking place in the acinus region of the pulmonary system for particles $<3 \mu \mathrm{m}$.[25]

The objective of this work is to experimentally investigate changes in aerosol particle diameter and particle number concentration of pharmaceutical aerosols under realistic inhalation and exhalation conditions, resulting in a calculated lung deposition. The active respiratory system model (xPULM) used in this work includes two core elements; a computed tomography (CT) derived mechanical upper airway model (UAM), and a primed porcine lung serving as human lung equivalent. This setup is used to represent a patient undergoing inhalation therapy. In contrast to widely spread measurement setups, this work integrates an optical aerosol spectrometer for inhalation and exhalation measurements to eliminate the drawbacks introduced by cascade impactors [24,30]. To cover a wide spectrum of devices used in clinical practice, five commonly used DPIs are investigated. Instead of focusing on PFIR, the focus was put on reaching a pressure drop of at least $\left(\mathrm{P}_{\mathrm{DROP}} \geq 1 \mathrm{kPa}\right)$ for all inhalers. This article aims to provide an alternative respiratory model suitable to reduce animal experimentation in aerosol research. Furthermore, the work aspires to mitigate the shortage of experimental data, viable to substitute demanding and constrictive experiments with human subjects. Moreover, the experimental setup including the $\mathrm{XPULM}^{\mathrm{TM}}$ model, can be seen as a basis for an alternative to animal testing, as the porcine lung, included in this trial, has been salvaged from an abattoir.

\section{Materials and Methods}

\subsection{Measurement Setup and Procedure}

The following two measurement trials were conducted during this study: A) Characterisation measurements and B) Respiration measurements. To assess the particles generated by the DPIs, Characterisation measurements were performed using a simple connection element to the respiratory model $\times \mathrm{PULM}^{\mathrm{TM}}$. This connector is characterised by a simplified version of the human laryngeal space, in form of a 90 degree bend and includes a sampling nozzle. This aerosol sampling point is in-line with the inhalatory airstream to ensure isoaxial aerosol sampling. Moreover, the control loop of the optical aerosol spectrometer ensures isokinetic sampling by maintaining a constant sampling flow, regardless of the inhalation flow profile. The active model of the human respiratory system, $\mathrm{xPULM}^{\mathrm{TM}}$, was used with polymer breathing bags, to simulate the inhalation effort of a patient during particle characterisation measurements. In the second step, Respiration measurements (see Figure 1) were conducted to investigate changes in aerosol particle diameter and particle number concentration during inhalation and exhalation. For this purpose, a primed porcine lung was used as a anatomically realistic lung equivalent. The porcine lung has been proven to be a suitable model of the anatomy of the human lung [31] and has been used in previous studies to research the pathogenesis of diseases such as cystic fibrosis [32]. The lung equivalent was connected to a mechanical UAM which was rapidly manufactured using 3D-printing techniques. The UAM is based on a clinically annotated CT examination of a healthy subject. In contrast to the characterisation measurements, sampling took place at the lower end of the mechanical UAM to assess the influence of its geometry on the measured values.The DPIs were mounted to the UAM using custom mouthpiece adapters for ensuring airtight connection. 


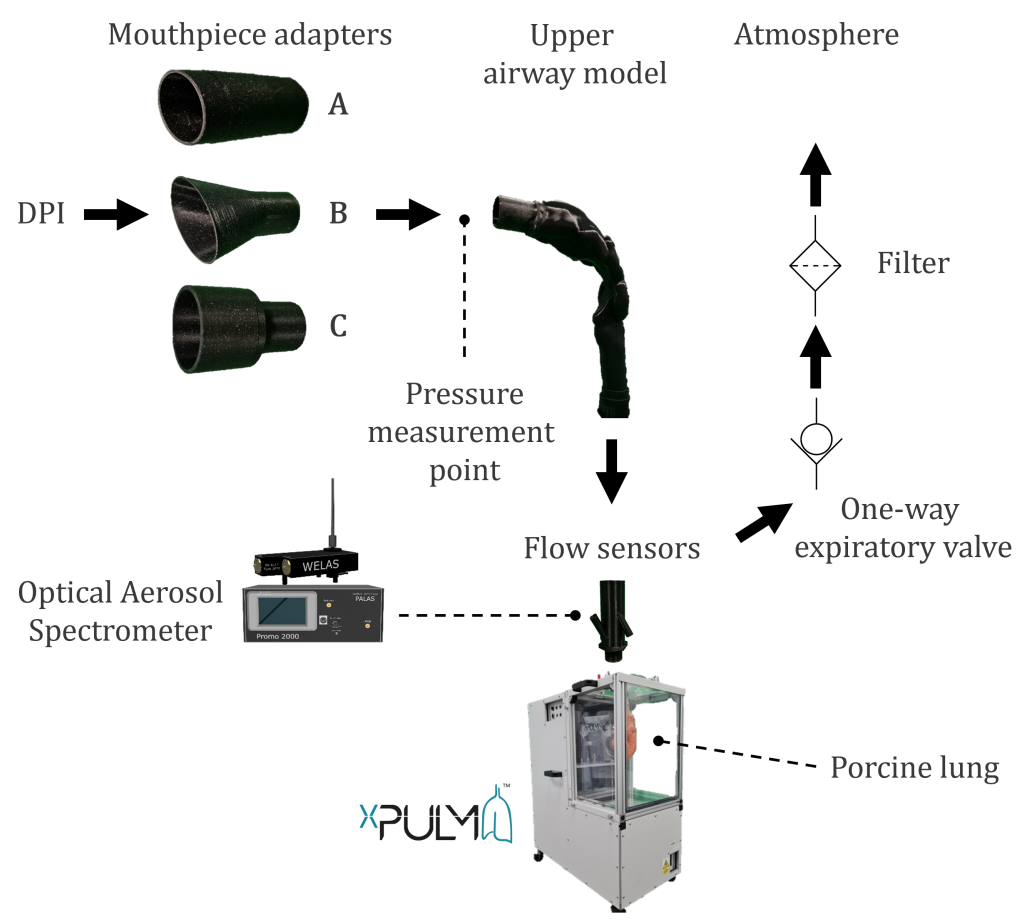

Figure 1. The measurement setup for Respiration measurements consisting of mouthpiece adapters for A) BreezHaler ${ }^{\circledR}$ B) Diskus ${ }^{\circledR}$, Ellipta ${ }^{\circledR}$, HandiHaler ${ }^{\circledR}$ C) Turbohaler ${ }^{\circledR}$, the mechanical UAM derived from CT examinations, optical aerosol spectrometer used to characterise the aerosol particles and the active model of the human respiratory system $\times \mathrm{PULM}^{\mathrm{TM}}$ with the porcine lung.

The measurement procedure of the Respiration measurements consists of three phases (i) inhalation, (ii) breath-hold, (iii) exhalation. Inhalation with maximum effort was simulated until the pressure drop across the DPI, measured with the FlowAnalyser PF-300 (IMT Analytics, Switzerland), reached at least the recommended pressure drop of $\geq 1 \mathrm{kPa}$ [8]. However, if achieveable, a pressure drop of $4 \mathrm{kPa}$, was targeted [33]. The driving force of the inhalation was terminated When the peak value of the pressure drop was reached. However, inhalation continued briefly, due to inertia and compliance of the lung equivalent. Inhaler-specific inhalation profiles were recorded using mass flow sensors SFM3000 (Sensirion, Switzerland).

The inhalation manoeuvre was followed by a $5 \mathrm{~s}$ breath-hold period prior to slow and steady exhalation at a flow of $30 \mathrm{~L} / \mathrm{min}$ for the duration of $6 \mathrm{~s}$. For each tested DPI, the measurements were repeated 12 times $(n=12)$. The in-/exhalation airstream was sampled by the optical aerosol spectrometer Promo 2000 (PALAS, Germany) connected to a white light aerosol sensor Welas 2070 (PALAS, Germany) with a constant flow rate of $5 \mathrm{~L} / \mathrm{min}$. This allowed for isokinetic measurement of particle size distribution and particle number concentration. The sensor is capable of measuring particles in the range of $0.2 \mu \mathrm{m}$ to $10 \mu \mathrm{m}$.

\subsection{Model of the Human Respiratory System}

The active model of the human respiratory system XPULM ${ }^{\mathrm{TM}}$ has been used in this study. The xPULM ${ }^{\mathrm{TM}}$ replicates human breathing efforts exerted during the use of DPIs. Fundamental respiratory characteristics (e.g., flow, pressure, and volume) of a rapidly inhaling human are captured during the simulation with high fidelity. Properties of the human respiratory system such as airway resistance and lung compliance are represented by using lung equivalents (porcine lungs) and mechanical UAMs (based on CT examinations). The displacement of gasses during spontaneous breathing occurs due to the pressure difference between the atmosphere and the human lung. This physiological process is recreated by the $x \mathrm{PULM}^{\mathrm{TM}}$. During the breathing simulation, pressure changes in the thoracic chamber are induced by the movement of a bellows system. For inhalation, a negative pressure is 
created in the chamber by expanding the bellows, leading to air following the pressure gradient resulting in inflation of the lung equivalent. During exhalation the opposite process occurs. The bellows is moved back to its original position, increasing the pressure in the chamber and deflating the lung equivalent. The movement of the bellows system can be precisely adjusted in the control software of the XPULM ${ }^{\mathrm{TM}}$. This allows for the simulation of different breathing scenarios under various conditions as demonstrated in [34]. A detailed description of the $\mathrm{xPULM}^{\mathrm{TM}}$ functionality and components including validation measurements are presented in our previous work [35].

\subsubsection{Representation of the Upper Respiratory Tract}

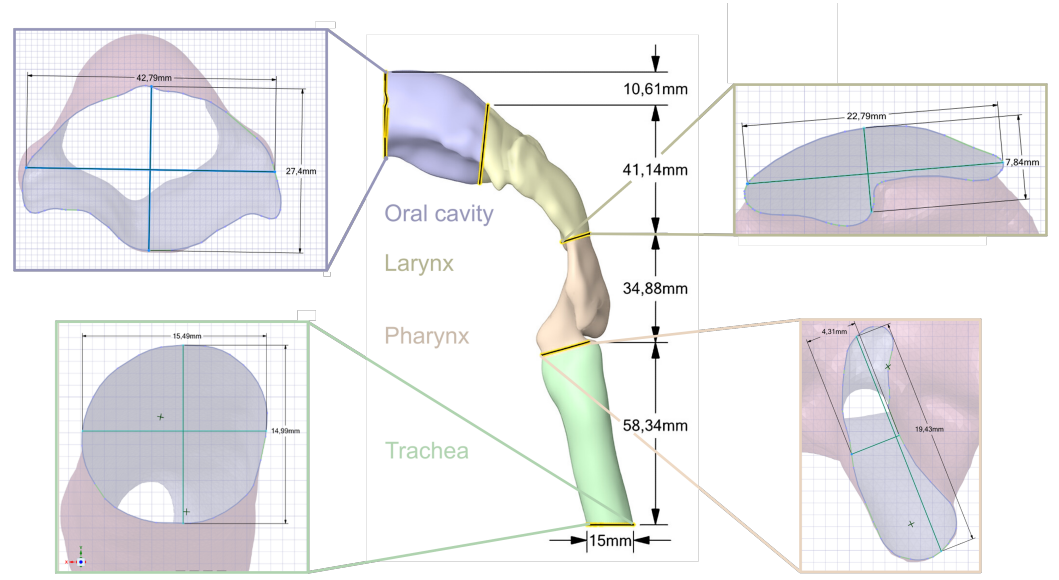

Figure 2. The manufactured 3D model of an upper respiratory tract of a 28-year-old, healthy, nonsmoking, male.

The mechanical UAM includes the oral cavity, oropharynx, larynx, and trachea. A CT examination of a 28-year-old, healthy, non-smoking, male was used for the UAM reconstruction. The subject has been annotated as healthy by clinical staff and did not show any sign of abnormal restrictions or geometrical limitations. Therefore, this CT examination has been considered to serve as a valid alternative to standardised airway models [36]. The selected dataset contained 280 images with a slice thickness of $0.75 \mathrm{~mm}$ and was exported in a Digital Imaging and Communications in Medicine (DICOM) format for further processing. The upper respiratory tract was segmented using a combination of thresholding and region growing techniques. The outcomes of the semi-automatic segmentation were inspected on a slide-by-slide basis and the segmentation parameters were adapted to obtain a precise segmentation of the upper airways. The resulting 3D model was exported as a Standard Triangle Language (STL) file and post-processed to be 3D-printable. The final 3D mechanical UAM was manufactured using rapid prototyping techniques and coated with resin. An emphasis was placed on positioning the model to minimise usage of support structure in the flow path. The dimensions for each section of the final model are summarised in Figure 2 and Table 1. Custom connectors were designed based on the geometry of each DPI to ensure an airtight connection between the inhaler and the mechanical UAM.

All rapidly produced components were manufactured from Polylactic acid (PLA) with a wall thickness of $2 \mathrm{~mm}$ and a layer height of $0.2 \mathrm{~mm}$. 
Table 1. Summary of the mechanical UAM dimensions of a 28-year-old, healthy, non-smoking, male. The sections correspond to the highlighted sections in Figure 2. SA - surface area

\begin{tabular}{llllllll}
\hline Section & $\begin{array}{l}\text { Volume } \\
{\left[\mathrm{mm}^{3}\right]}\end{array}$ & $\begin{array}{l}\text { Lower SA } \\
{\left[\mathrm{mm}^{2}\right]}\end{array}$ & $\begin{array}{l}\text { Diameter Y } \\
{[\mathrm{mm}]}\end{array}$ & $\begin{array}{l}\text { Dimeter X } \\
{[\mathrm{mm}]}\end{array}$ & $\begin{array}{l}\text { Upper SA } \\
{\left[\mathrm{mm}^{2}\right]}\end{array}$ & $\begin{array}{l}\text { Diameter Y } \\
{[\mathrm{mm}]}\end{array}$ & $\begin{array}{l}\text { Diameter X } \\
{[\mathrm{mm}]}\end{array}$ \\
\hline Trachea (green) & 10657.02 & 188.39 & 15.49 & 14.99 & 86.60 & 18 & 4.93 \\
Pharynx (orange) & 7311.52 & 119.06 & 19.43 & 4.31 & 86.60 & 4.86 & 24.51 \\
Larynx (yellow) & 15902.39 & 119.11 & 7.84 & 22.79 & 777.57 & 24.93 & 44.34 \\
Oral cavity (blue) & 22265.60 & 777.60 & 7.84 & 22.79 & 529.90 & 7.84 & 22.79 \\
\hline
\end{tabular}

\subsubsection{Representation of the Lower Respiratory tract}

The lower respiratory tract consists of the bronchi, bronchioles, and alveoli, which form the lung. During breathing simulations, these structures have been represented by a primed porcine lung. The lung was salvaged from a slaughterhouse process and is therefore compliant with the 3R principles [37] which denote responsible use of animal or animal organs during experiments. The Nasco-guard ${ }^{\circledR}$ (Nasco, Wisconsin, USA) preservation process keeps the porcine lung inflatable, elastic and covered with the parietal pleura. These properties are necessary for physiologically and anatomically realistic simulations of human breathing.

\subsection{Dry Powder Inhalers}

In total, five DPIs were evaluated in this study, grouped into single-dose and multiple dose inhalers. The single-dose devices (BreezHaler ${ }^{\circledR}$ and HandiHaler ${ }^{\circledR}$ ) are loaded with a capsule containing the dose which is punctured prior to use. The remaining three were multi-dose DPIs (Diskus $®$, Ellipta ${ }^{\circledR}$, Turbuhaler ${ }^{\circledR}$ ) which store multiple doses within the devices. Outlets of all DPIs were modified with custom rapidly manufactured adaptors to enable well-fitted, airtight, connection to the oral cavity of the mechanical UAM.

Table 2. Summary of the relevant parameter values of the used DPIs taken from literature [8,38].

\begin{tabular}{|c|c|c|c|c|c|}
\hline Device & Active substance & $\begin{array}{l}\text { Resistance } \\
{\left[\mathrm{kPa}^{1 / 2} / \mathrm{L} / \mathrm{min}\right]}\end{array}$ & $\begin{array}{l}\text { Metered Dose } \\
{[\mu \mathrm{g}]}\end{array}$ & $\begin{array}{l}\text { Lactose } \\
{[\mathrm{mg}]}\end{array}$ & Dose type \\
\hline Seebri® Breezhaler ${ }^{\circledR}$ & Glycopyrronium & 0.0216 & 44 & 23.6 & single-dose, hard capsules \\
\hline Seretide ${ }^{\circledR}$ Diskus ${ }^{\circledR}$ & Salmeterol and fluticasone propionat & 0.0254 & $50 / 500$ & 12.5 & multi-dose, pre-dispensed \\
\hline Anoro® Ellipta ${ }^{\circledR}$ & Fluticasone furoate and vilanterol & 0.0286 & $55 / 22$ & 25 & multi-dose, pre-dispensed \\
\hline Spiriva ${ }^{\circledR}$ HandiHaler ${ }^{\circledR}$ & Tiotropium bromide & 0.0504 & 18 & 5.5 & single-dose, hard capsules \\
\hline Symbicort ${ }^{\circledR}$ Turbohaler ${ }^{\circledR}$ & Budesonide and formoterol & 0.0313 & $200 / 6$ & 0.73 & multi-dose, pre-dispensed \\
\hline
\end{tabular}

\section{2.4. Data Processing and Statistics}

The optical aerosol spectrometry measurements were conducted with 128 intervals per decade. The arithmetic centre of the intervals $\left(x_{i}\right)$ is then:

$$
x_{i}=x_{i, \text { lower }}+\frac{x_{i, \text { upper }}-x_{i, \text { lower }}}{2}=x_{i, \text { lower }}+\frac{\Delta x_{i}}{2}[\mu \mathrm{m}]
$$

For further calculations, the differential particle number distribution $q_{0}\left(x_{i}\right)$ is defined as:

$$
q_{0}\left(x_{i}\right)=\frac{1}{\sum n_{i}} \frac{n_{i}}{\Delta x_{i}}\left[\mu m^{-1}\right]
$$

where $n_{i}$ is the measured particle number within the interval limits $x_{i, l o w e r}$ and $x_{i, \text { upper }}$. Leading to the mean particle diameter $M_{1}$ calculation:

$$
M_{1}=\sum x_{i} q_{0}\left(x_{i}\right) \Delta x_{i}=\bar{x}[\mu m]
$$


Further information about the inhaled aerosol is obtained by calculating the particle number concentration:

$$
d C n=n_{i} \frac{1}{V_{m}}\left[P / \mathrm{cm}^{3}\right]
$$

where the measured volume $V_{m}$ is defined as:

$$
V_{m}=u \text { Iw } t_{\text {measurement }}\left[\mu^{3}\right]
$$

8 3. Results and Discussion

- 3.1. Inspiratory flow rate and pressure drop measurements compared to a critical $\chi^{2}=3.841$ for a degree of freedom $d f=1$.

The measurement data is evaluated with non-parametric methods as the requirements for normal distribution and hence parametric test methods are not fulfilled. The data groups are compared pairwise using the Kruskal-Wallis test by ranks (or one-way ANOVA on ranks) with a significance level of $\alpha=0.05, \mathrm{H}$ values and $\mathrm{p}$ values are calculated and
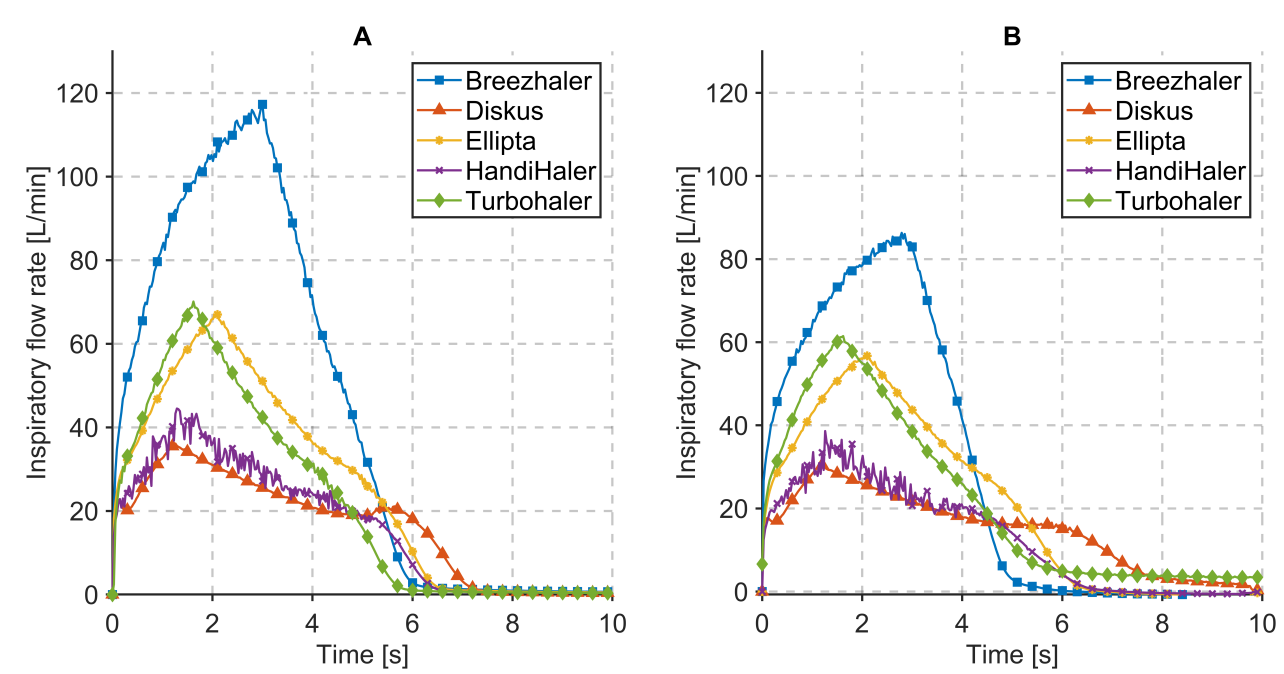

Figure 3. Flow profiles during A) Characterisation measurements B) Respiration measurements while inhaling through Breezhaler ${ }^{\circledR}$, Diskus ${ }^{\circledR}$, Ellipta ${ }^{\circledR}$, HandiHaler ${ }^{\circledR}$ and Turbohaler ${ }^{\circledR}$ at a pressure drop given in Table 3.

Flow profiles measured during Characterisation and Respiration measurements for the evaluated DPIs are presented in Figure 3. During Characterisation measurements, the resistance of the system is primarily resulting from the inner resistance of the DPIs. The peak inspiratory flow, measured at the pressure drop values, provided in 3, ranges from 71 to $120 \mathrm{~L} / \mathrm{min}$. The shape of the inhalation profile, shown in Figure $3 \mathrm{~A}$ is characteristic for each used DPIs and reflects the individual constructional solution of the devices included in this evaluation. Vibrations of the capsule, for example, are distinctive for HandiHaler ${ }^{\circledR}$ and manifest in rapid oscillations of the inspiratory flow. Inhalation time required to reach the necessary pressure drop is influenced by the inner resistance of the DPIs. The shape of the measured flow profiles with XPULM ${ }^{\mathrm{TM}}$ are comparable to full flow-rate profiles of patients [38].

The inspiratory flow rate during Respiration measurements is, in contrast to Characterisation measurements, influenced by resistance and compliance of the included mechanical UAM and the primed porcine lung, respectively. This is evident for DPIs with low inner resistance (e.g., Breezhaler ${ }^{\circledR}$ ) where the inspiratory flow rate drops by $30 \mathrm{~L} / \mathrm{min}$. The DPIs with high inner resistance (e.g., HadiHaler $\left.{ }^{\circledR}\right)$ are influenced moderately as the increase of the overall system resistance is lower. The peak inspiratory flow, measured at the pressure drop values, provided in 3 , ranges from 61 to $89 \mathrm{~L} / \mathrm{min}$. 
The flow results of the different DPIs, as shown in Figure 3, allow conclusions on the handling of the inhaler and its characteristics during use. The HandiHaler ${ }^{\circledR}$ for example shows a wider range of flow values as well as higher volatility in pressure drop values (see Figure 4), than most of the other inhalers. This is mainly caused by the propelling mechanism, which is based on the mechanical movement of the aerosol loaded capsule. Based on the user guide, the capsule has to move (also acoustically noticeable) within the inhaler, in order to disperse the powder. This oscillating movement leads to a volatile flow and oscillating pressure drop measurements, therefore, characterisation of this inhaler is influenced by the handling of the capsule and inhaler.

A comparable observation can be made for the use of the second capsule-based DPI, the Breezhaler ${ }^{\circledR}$. This product is also based on the oscillation of the capsule in order to propel the aerosol properly. These oscillations are moreover influenced by the holding position and angle of the device during inhalation. In contrast to the HandiHaler ${ }^{\circledR}$, the capsule within the Breezhaler ${ }^{\circledR}$ is not limited in movement mechanically, but mainly by gravitation. When the Breezhaler ${ }^{\circledR}$ is moved to a horizontal position the likelihood of the capsule dropping out of the holding cavity increases, impacting the aerosol production mechanism. The correspondingly changed flow profiles caused by different lung equivalents can be observed in Figure 3. The compliance of the introduced lung tissue (depicted by the flow curves in Figure 3B) influences the peak flow as well as the flow profile. The anatomic components of the used porcine lung and its geometric properties lead to a prolonged inhalation time and flattened flow profile when using identical inhalation settings as with the polymer breathing bags as lung equivalent.

\subsection{Influence of the mechanical UAM and the primed porcine lung}
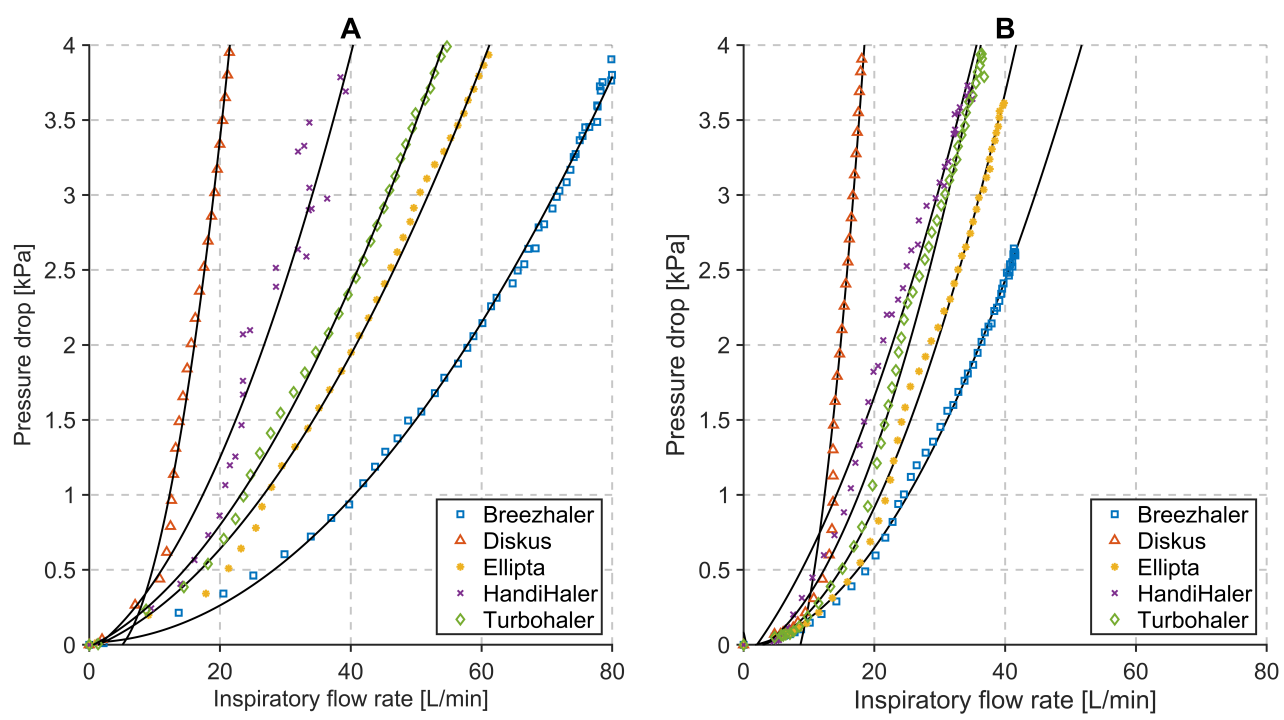

Figure 4. Relationships between inspiratory flow rate and pressure drop of five commercial DPIs during A) Characterisation measurements B) Respiration measurements.

Effects of the mechanical UAM and the primed porcine lung during Respiration measurements are evident from the relationship between inspiratory flow rate and pressure drop across the inhalers, see Figure 4B). The resistance of the measurement system increases significantly $(\mathrm{p}<0.05)$ with all inhalers (see Table 3$)$ and a pressure drop of $4 \mathrm{kPa}$ is reached for lower inspiratory flow rates.

The measurements revealed limitations in reaching the pressure drop of $4 \mathrm{kPa}$ consistently for Breezhaler ${ }^{\circledR}$. Based on the recorded observations, the position of the capsule within the DPI, as well as the angle of the device are critical. Even a slight movement of the capsule changes the behaviour of the device. The pressure drop set prior to measurements could not be reached despite high inspiratory flow and prolonged inhalation time. A 
Table 3. Summary of the relevant parameter values for the used DPIs, during Characterisation and Respiration measurements. Where: $\mathrm{V}_{\mathrm{INH}}$ - inhaled volume, $\mathrm{P}_{\mathrm{DROP}}$ - pressured drop across the inhaler during inhalation, PIF - peak inspiratory flow, and $\mathrm{t}_{\mathrm{INH}}$ - inhalation time.

\begin{tabular}{|c|c|c|c|c|c|c|c|c|c|c|}
\hline \multirow{2}{*}{$\begin{array}{l}\text { Dry powder inhalers } \\
\text { Device }\end{array}$} & \multicolumn{5}{|c|}{ Characterisation parameters } & \multicolumn{5}{|c|}{ Respiration parameters } \\
\hline & $\begin{array}{l}\text { Vinh } \\
\text { [L] }\end{array}$ & $\begin{array}{l}\mathrm{P}_{\mathrm{DROP}} \\
{[\mathrm{kPa}]}\end{array}$ & $\begin{array}{l}\mathrm{PIF} \\
{[\mathrm{L} / \mathrm{min}]}\end{array}$ & $\begin{array}{l}\text { tinh } \\
{[\mathrm{s}]}\end{array}$ & $\begin{array}{l}\text { Resistance } \\
{\left[\mathrm{kPa}^{1 / 2} / \mathrm{L} / \mathrm{min}\right]}\end{array}$ & $\begin{array}{l}\text { Vinh } \\
{[\mathrm{L}]}\end{array}$ & $\begin{array}{l}\mathrm{P}_{\mathrm{DROP}} \\
{[\mathrm{kPa}]}\end{array}$ & $\begin{array}{l}\mathrm{PIF} \\
{[\mathrm{L} / \mathrm{min}]}\end{array}$ & $\begin{array}{l}\text { tinh } \\
{[\mathrm{s}]}\end{array}$ & $\begin{array}{l}\text { Resistance } \\
{\left[\mathrm{kPa}^{1 / 2} / \mathrm{L} / \mathrm{min}\right]}\end{array}$ \\
\hline Seebri ${ }^{\circledR}$ Breezhaler ${ }^{\circledR}$ & 6.98 & 3.99 & 120.12 & 3.00 & 0.0166 & 4.55 & 2.71 & 89.25 & 3.00 & $0.0185^{*}$ \\
\hline Seretide ${ }^{\circledR}$ Diskus ${ }^{\circledR}$ & 2.55 & 4.10 & 36.33 & 1.20 & 0.0557 & 2.32 & 3.88 & 30.74 & 1.20 & $0.0641^{*}$ \\
\hline Anoro ${ }^{\circledR}$ Ellipta ${ }^{\circledR}$ & 4.06 & 4.36 & 68.39 & 2.10 & 0.0305 & 3.38 & 3.63 & 57.42 & 2.10 & $0.0332 *$ \\
\hline Spiriva ${ }^{\circledR}$ HandiHaler ${ }^{\circledR}$ & 2.60 & 4.36 & 50.79 & 1.40 & 0.0411 & 2.05 & 3.73 & 43.81 & 1.40 & $0.0441^{*}$ \\
\hline Symbicort ${ }^{\circledR}$ Turbohaler ${ }^{\circledR}$ & 3.52 & 3.04 & 71.31 & 1.60 & 0.0279 & 3.95 & 4.03 & 61.83 & 1.60 & $0.0325^{*}$ \\
\hline
\end{tabular}

${ }^{*} \mathrm{p}<0.05$ for difference between resistances measured with and without the mechanical UAM

pressure drop $\geq 1 \mathrm{kPa}$ with any DPI is sufficient for the patient to receive an adequate lung dose [8]. This criterion (defined as a minimum requirement) was met over all conducted measurements.

Relevant parameter values for the used DPIs, Characterisation measurements and Respiration measurements are summarised in Table 3. These parameter values complement the graphical result shown in Figure 3 and Figure 4. Additionally, they provide further inside about the relationship between the inner resistance of the DPIs, inhaled volume, inhalation time and peak inspiratory flow at particular pressure drop values.

The difference between the inner resistances of DPI measured during characterisation and the values extracted from the literature is in an acceptable tolerance range of $\pm 0.01 \mathrm{kPa}^{1 / 2} / \mathrm{L} / \mathrm{min}$, with the exception of Diskus ${ }^{\circledR}$ (see Table 2 and Table 3). Results show, that the Diskus ${ }^{\circledR}$ inhaler, which was included in the measurement setup, exhibits high inner resistance of $0.0557 \mathrm{kPa}^{1 / 2} / \mathrm{L} / \mathrm{min}$. However, these results do not fully align with characterisation values provided by other groups. The calculated inner resistance of a Diskus ${ }^{\circledR}$ inhaler has been published with $0.0254 \mathrm{kPa}^{1 / 2} / \mathrm{L} / \mathrm{min}$, similar to the values for an Ellipta ${ }^{\circledR}$ DPI $[8,38]$. This discrepancy was potentially caused by suboptimal storage conditions for this inhaler.

\subsection{Changes in mean particle diameter}

Changes in mean particle diameter $\left(M_{1}\right)$ during DPI Characterisation and Respiration measurements using the mechanical UAM and primed porcine lung are depicted in Figure 5. During characterisation measurements the mean particle diameter ranges from $0.95 \mu \mathrm{m}$ (TurboHaler ${ }^{\circledR}$ ) to $2.99 \mu \mathrm{m}$ (Diskus ${ }^{\circledR}$ ). These results are comparable to literature values reporting particles ranging from $2.20 \mu \mathrm{m}$ (Ellipta ${ }^{\circledR}$ ) to $3.90 \mu \mathrm{m}$ (HandiHaler ${ }^{\circledR}$ ) [38]. Differences in the absolute values of mean particle diameter are to be expected, based on the different components of the used measurement setup. As reported by several authors $[8,9,38,39]$ the aerodynamic properties of the generated drug particles vary based on quantities such as peak inspiratory flow rate, flow acceleration, inhalation time and inhaled volume. These quantities are patient-specific and vary from the presented measurements. Filtration properties of the mechanical UAM cause the mean particle diameter to shift towards lower values during inhalation. This can be observed for all tested DPI, as Figure 5 depicts. It has been shown, that the upper respiratory tract indeed acts as a particulate filter. Larger particles $(>3 \mu \mathrm{m})$ deposit more easily in the upper respiratory tract. While the smaller particles $(<3 \mu \mathrm{m})$ pass into the lower respiratory tract as the filtration function decreases with particle size. [40,41] 

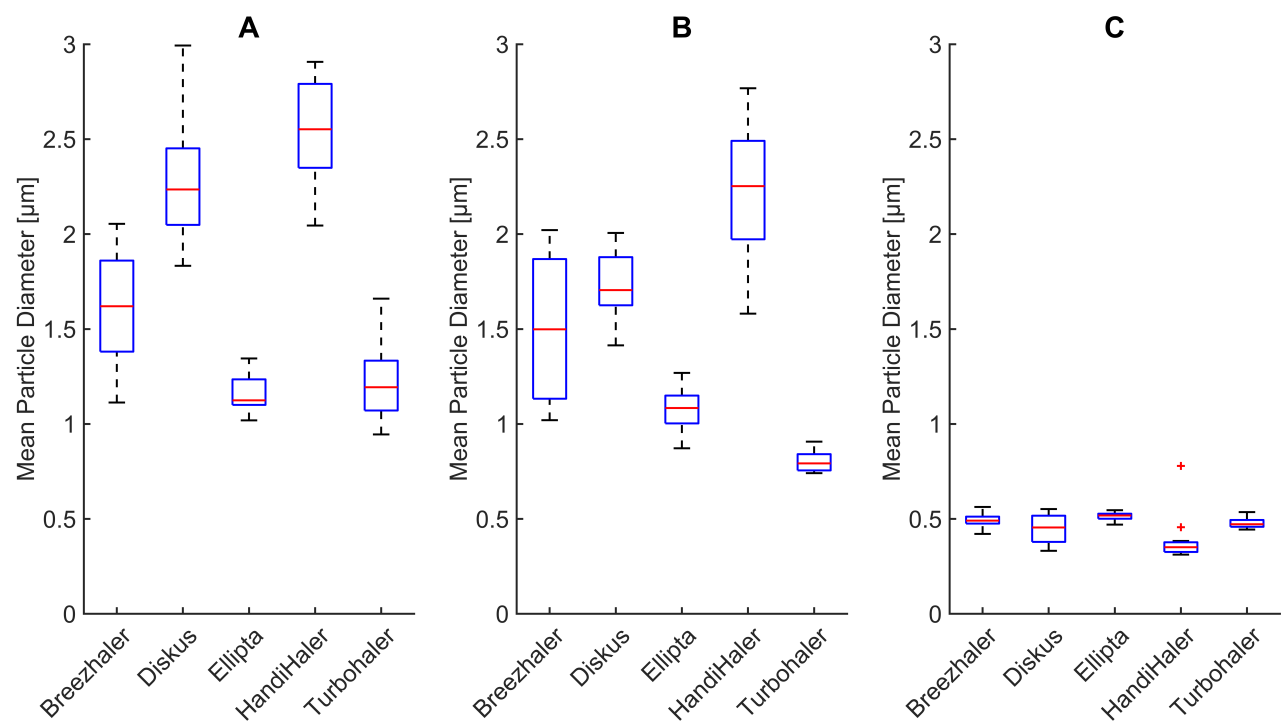

Figure 5. Changes in mean particle diameter during A) Characterisation measurements B) Inhalation measurements C) Exhalation measurements for five commercial DPIs

Exhaled particles during our measurements are characterised by a mean particle diameter in a narrow range from $0.31 \mu \mathrm{m}$ (HandiHaler $\left.{ }^{\circledR}\right)$ to $0.56 \mu \mathrm{m}$ (BreezHaler $\left.{ }^{\circledR}\right)$. These results were expected as the deposition of aerosol particles in the lung reaches its minimum at $0.5 \mu \mathrm{m}[42,43]$. Furthermore, there is a significant difference $(\mathrm{p}<0.05)$ in mean particle diameter between inhaled and exhaled particles Figure 5B) \& C) for all tested DPIs (K-W test, $\mathrm{H}=17.29, \mathrm{p}=0.00003$ ). This change is caused by the interaction of the aerosol particles with the primed porcine lung tissue. The interaction is caused by a highly complex and constantly changing inner geometry of the lung tissue, which influences the mean particle diameter. Additionally, the high relative humidity within the lung tissue may lead to hygroscopic growth and therefore also to adhesion of particles.

\subsection{Deposition of particles in the porcine lung}

The difference between the particle number concentration in inhaled and exhaled air can be considered as number concentration of particles depositing in the porcine lung. The deposition is expressed as a percentage of particle number concentration averaged over the individual inhalation or exhalation cycles and depicted in Figure 6.

Differences between aerosol particle number concentration sampled from the air stream during A) Inhalation and B) Exhalation for all inhalers are depicted in Figure 7. There is a statistically significant difference $(p<0.05)$ between particle number concentration in inhaled and exhaled airstream for all tested inhalers (K-W test, $\mathrm{H}=17.29, \mathrm{p}=$ 0.00003 ). This is caused by particles depositing in the primed porcine lung.

The generated drug particles from the DPIs are inhaled through the mechanical UAM which represents the naso-oro-pharyngo-laryngeal region (extrathoracic region). Larger particles $(>3 \mu \mathrm{m})$ deposit in this region mainly due to effects of inertial impaction [43]. The rest of the drug particles penetrates the deeper regions of the respiratory tract model and reach the primed porcine lung. The complex geometry and high relative humidity of the lung present an ideal environment for most of the particles to deposit due to sedimentation and Brownian diffusion [21,43].

Regional lung deposition and bronchodilator response of pharmaceutical aerosols was studied extensively in previous works $[44,45]$. Their results confirm that small particles are exhaled with exhalation fractions for particle diameters $1.5 \mu \mathrm{m}, 3 \mu \mathrm{m}$ and $6 \mu \mathrm{m}$ being $22 \%$, $8 \%$, and $2 \%$ respectively [45]. A lung deposition study in healthy human subjects showed a exhalation fraction of exhaled dose of $1.2 \%$ [46]. In this study, however, a MAGhaler DPI was used to aerosolise the powder. 


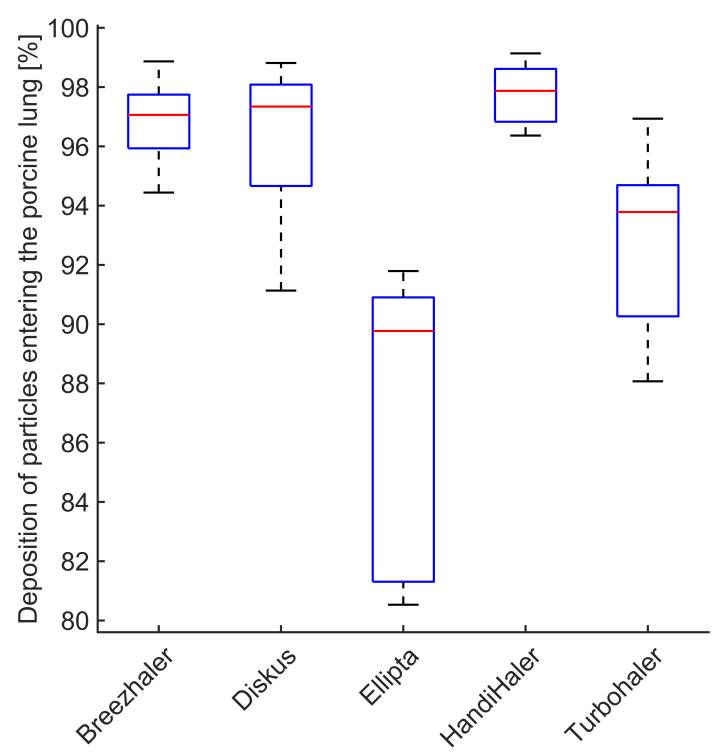

Figure 6. Deposition of aerosol particles in the porcine lung (expressed as a percentage of particle number concentration measured posterior of the mechanical UAM) for five commercial DPIs inhalers.

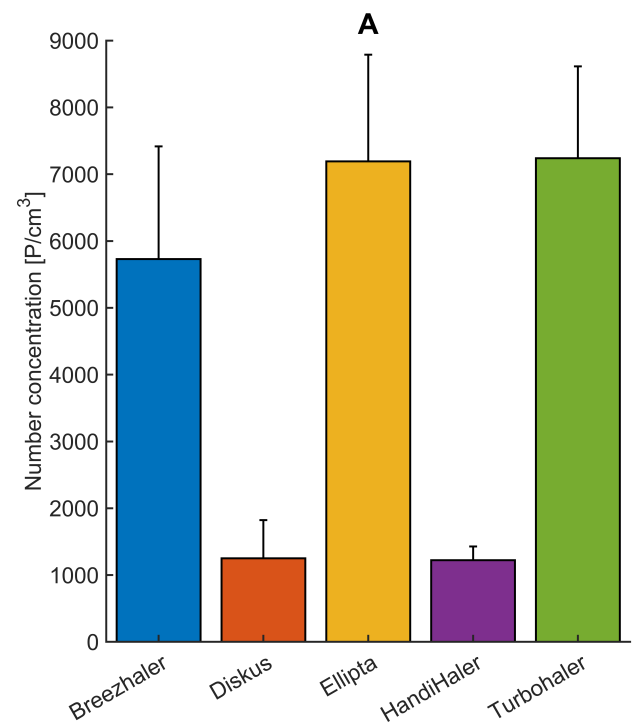
(Turbohaler®).
Research conducted with healthy individuals, asthmatic and COPD patients show no significant difference in drug deposition of aerosols generated with DPIs [47]. The reported fraction of exhaled particles ranges between $1.6 \%$ and $3.3 \%$. These findings are consistent with our measurements where the mean number concentrations exhaled are 2.94\% (BreezHaler ${ }^{\circledR}$ ), 2.66\% (Diskus ${ }^{\circledR}$ ), 10.24\% (Ellipta ${ }^{\circledR}$ ) 2.13\% (HandiHaler ${ }^{\circledR}$ ) and $6.22 \%$

Figure 7. Differences between aerosol particle number concentration sampled from the air stream during A) Inhalation and B) Exhalation for five commercial DPIs. Respiration parameters are provided in Table 3.

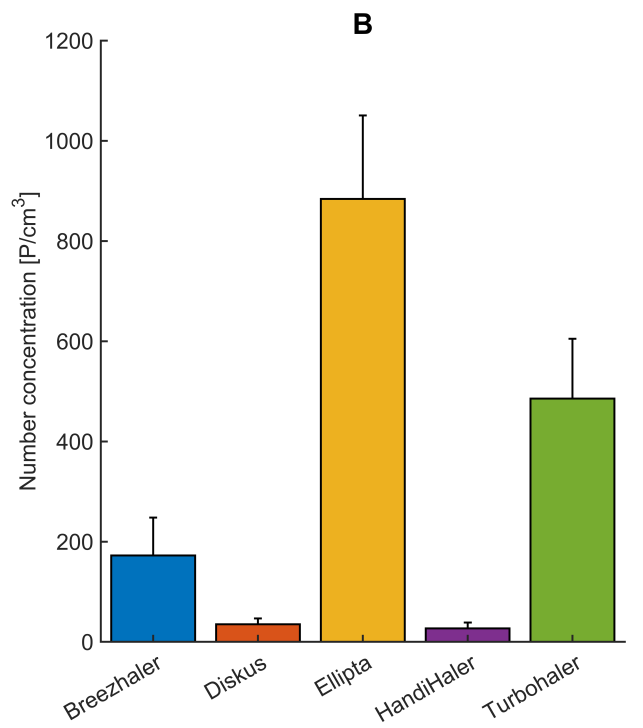

\section{Summary and Conclusion}

For a large number of patients, DPIs are the device of choice for the delivery of pharmaceuticals to manage asthma and COPD $[9,48]$. The number of commercially available DPIs is growing [8] with inhalers varying in their design, operating mechanisms, and resistance to inhaled airflow $[8,49]$. Accounting for these properties and the patient's ability to use the specific device is essential for efficient drug delivery. Testing setups provide 
an option to evaluate aerosolised dry powders generated by DPIs and allow for further insights into DPI performance under various conditions [50-53].

In this work, aerosol particle diameter and particle number concentration of pharmaceutical aerosols generated by five commercially available DPIs were investigated. The measurement setup consists of the active respiratory system model XPULM ${ }^{\mathrm{TM}}$ in combination with optical aerosol spectrometry and a mechanical UAM. This allows for the evaluation of pharmaceutical aerosols in the range of $0.2 \mu \mathrm{m}$ to $10 \mu \mathrm{m}$ and the calculation of deposition of particles in the porcine lung under realistic inhalation and exhalation simulations. Experimental data measured during exhalation are scarce when in-vitro pharmaceutical aerosol test systems are employed due to the operating principle of impactors.

To represent the human upper respiratory tract with high fidelity a mechanical UAM was developed, manufactured, and introduced as a part of the XPULM ${ }^{\mathrm{TM}}$. The model was derived from CT examinations of a 28 -year-old healthy male, which has been clinically annotated as healthy and therefore as physiologically representative. A primed porcine lung was used to simulate the complex inner structures of the human lower respiratory tract. The integration of the mechanical UAM and primed porcine into the $\mathrm{xPULM}^{\mathrm{TM}}$ model represents an important step forward towards the realistic simulation of a breathing human. Additionally, the combination of $\mathrm{xPULM}^{\mathrm{TM}}$ with an optical aerosol spectrometer presents an alternative approach to animal experimentation suitable for applications in aerosol research.

Our results can be summarised as follows:

- Integration of a mechanical UAM, as a part of the $\mathrm{XPULM}^{\mathrm{TM}}$, increases the resistance of the overall system. This affects inhalatory flow and pressure characteristics of DPIs with lower inner resistance more than DPIs with high inner resistance, where the change is negligible.

- Inclusion of a porcine lung as a representation of the human lower respiratory tract (compliant with the $3 \mathrm{R}$ principles) allows comparable particle deposition to reported findings [45-47].

- Handling and placement of a capsule into single-dose DPIs influences aerosol production during inhalation drug therapy. Slight changes in capsule placement may influence the amount of delivered drug. Correct handling of the inhaler should be emphasised alongside acceptable inhalation manoeuvres (as defined by the device manufacturer) to ensure the desired result.

- Mean particle diameter is reduced by the filtration properties of the mechanical UAM, affecting mostly larger particles $(>3 \mu \mathrm{m})$. Such models, when based on CT examinations, are reliably representing the function of the human upper respiratory tract.

- The majority of particles entering the porcine lung deposit within, minimum deposition is reached for the particle size of $(0.5 \mu \mathrm{m})$. The primed porcine lung is therefore a suitable lung equivalent and representation of the human lung.

- Sampling of the airstream during inhalation and exhalation and its subsequent evaluation using optical aerosol spectrometry techniques is a viable alternative to impactors for evaluating pharmaceutical aerosols.

In conclusion, the XPULM ${ }^{\mathrm{TM}}$ active respiratory system model in combination with the introduced mechanical UAM and the optical aerosol spectrometer is a viable option for investigating particle diameter and particle number concentration of pharmaceutical aerosol depositing in the porcine lung under realistic breathing conditions. The model can support the reduction of animal experimentation in aerosol research and provide an alternative to experiments with human subjects. Further research will focus on the inclusion of additional components and techniques (e.g., nano-dots, tissue sampling, histopathology) to quantify the regional deposition of pharmaceutical aerosols in lung tissue obtained by $3 R$ compliant processes. Additionally, coating of the inner surface of the mechanical UAM will be considered, to ensure the least possible artifacts and interference of the 3D printing materials on the particle transportation effects. Besides regional deposition, also 
194

mass-based approaches will be included, to further increase comparability with established deposition measurement techniques.

Author Contributions: Richard Pasteka: Conceptualization, Methodology, Validation, Data curation, Writing- Original draft preparation, Visualization, Investigation Lara Schöllbauer: Investigation, Writing- Reviewing and Editing, Pedro Santo da Costa: Formal analysis, Writing- Reviewing Radim Kolar: Writing- Reviewing and Editing, Mathias Forjan: Conceptualization, Investigation, WritingReviewing and Editing, Supervision.

Funding: This research received no external funding.

Institutional Review Board Statement: Not applicable

Informed Consent Statement: Not applicable

Data Availability Statement: The data that support the findings of this study are available upon reasonable request.

Acknowledgments: The authors would like to thank F. Enghuber and M. Malaskova, for their valuable contributions during the creation of this manuscript.

Conflicts of Interest: The authors declare no conflict of interest.

\section{References}

1. Forum of International Respiratory Societies. The Global Impact of Respiratory Disease; European Respiratory Society, 2017.

2. Eurostat. Respiratory diseases statistics - Statistics Explained; 2020. Available at https://ec.europa.eu/eurostat/statistics-explained/ index.php?title=Respiratory_diseases_statistics\&oldid=497079.

3. Sorino, C.; Negri, S.; Spanevello, A.; Visca, D.; Scichilone, N. Inhalation therapy devices for the treatment of obstructive lung diseases: the history of inhalers towards the ideal inhaler. European Journal of Internal Medicine 2020, 75, 15-18. doi:10.1016/J.EJIM.2020.02.023.

4. Stein, S.W.; Thiel, C.G. The History of Therapeutic Aerosols: A Chronological Review. Journal of Aerosol Medicine and Pulmonary Drug Delivery 2017, 30, 20-41. doi:10.1089/jamp.2016.1297.

5. Wintemute, K.; Miller, F. Dry powder inhalers are environmentally preferable to metered-dose inhalers. CMAJ 2020, 192, E846E846. doi:10.1503/CMAJ.75949.

6. Rau, J.L. Practical problems with aerosol therapy in COPD. Respiratory Care 2006, 51, 158-172.

7. Geller, D.E. Comparing Clinical Features of the Nebulizer, Metered-Dose Inhaler, and Dry Powder Inhaler. Respiratory Care 2005, 50, 1313-1322, [http:/ /rc.rcjournal.com/content/50/10/1313.full.pdf].

8. Clark, A.R.; Weers, J.G.; Dhand, R. The Confusing World of Dry Powder Inhalers: It Is All about Inspiratory Pressures, Not Inspiratory Flow Rates. Journal of Aerosol Medicine and Pulmonary Drug Delivery 2020, 33, 1-11. doi:10.1089/jamp.2019.1556.

9. Atkins.; Smaldone.; MacIntyre.; Hickey.; Amato, M.T. Dry powder inhalers: An overview - Discussion. Respiratory Care 2005, $50,1312$.

10. Mahler, D.A.; Waterman, L.A.; Gifford, A.H. Prevalence and COPD phenotype for a suboptimal peak inspiratory flow rate against the simulated resistance of the diskus ${ }^{\circledR}$ dry powder inhaler. Journal of Aerosol Medicine and Pulmonary Drug Delivery 2013, 26, 174-179. doi:10.1089/jamp.2012.0987.

11. Grant, A.C.; Walker, R.; Hamilton, M.; Garrill, K. The ELLIPTA ${ }^{\circledR}$ dry powder inhaler: Design, functionality, in vitro dosing performance and critical task compliance by patients and caregivers. Journal of Aerosol Medicine and Pulmonary Drug Delivery 2015, 28, 474-485. doi:10.1089/jamp.2015.1223.

12. Mahler, D.A. Peak inspiratory flow rate as a criterion for dry powder inhaler use in chronic obstructive pulmonary disease. Annals of the American Thoracic Society 2017, 14, 1103-1107. doi:10.1513/AnnalsATS.201702-156PS.

13. Duarte, A.G.; Tung, L.; Zhang, W.; Hsu, E.S.; Kuo, Y.F.; Sharma, G. Spirometry measurement of peak inspiratory flow identifies suboptimal use of dry powder inhalers in ambulatory patients with COPD. Chronic Obstructive Pulmonary Diseases 2019, 6, $246-255$. doi:10.15326/jcopdf.6.3.2018.0163.

14. Chen, S.Y.; Huang, C.K.; Peng, H.C.; Yu, C.J.; Chien, J.Y. Inappropriate Peak Inspiratory Flow Rate with Dry Powder Inhaler in Chronic Obstructive Pulmonary Disease. Scientific Reports 2020, 10, 1-9. doi:10.1038/s41598-020-64235-6.

15. Taki, M.; Marriott, C.; Zeng, X.M.; Martin, G.P. Aerodynamic deposition of combination dry powder inhaler formulations in vitro: A comparison of three impactors. International Journal of Pharmaceutics 2010, 388, 40-51. doi:10.1016/j.jpharm.2009.12.031.

16. Versteeg, H.K.; Roberts, D.L.; Chambers, F.; Cooper, A.; Copley, M.; Mitchell, J.P.; Mohammed, H. A cross-industry assessment of the flow rate-elapsed time profiles of test equipment typically used for dry-powder inhaler (DPI) testing: Part 2- analysis of transient air flow in the testing of DPIs with compendial cascade impactors. Aerosol Science and Technology 2020, 54, 1448-1470. doi:10.1080/02786826.2020.1792825.

17. Greguletz, R.; Andersson, P.U.; Cooper, A.; Chambers, F.; Copley, M.A.; Daniels, G.; Hamilton, M.; Hammond, M.; Mohammed, H.; Roberts, D.L.; Shelton, C.; Versteeg, H.K.; Mitchell, J.P. A cross-industry assessment of the flow rate-time profiles of test 
equipment typically used for dry-powder inhaler (DPI) testing: Part 1-compendial apparatuses. Aerosol Science and Technology 2020, 54, 1424-1447. doi:10.1080/02786826.2020.1792824.

18. Wei, X.; Hindle, M.; Kaviratna, A.; Huynh, B.K.; Delvadia, R.R.; Sandell, D.; Byron, P.R. In vitro tests for aerosol deposition. VI: Realistic testing with different mouth-throat models and in vitro - In vivo correlations for a dry powder inhaler, metered dose inhaler, and soft mist inhaler. Journal of Aerosol Medicine and Pulmonary Drug Delivery 2018, 31, 358-371. doi:10.1089/jamp.2018.1454.

19. Ravi Kannan, R.; Przekwas, A.J.; Singh, N.; Delvadia, R.; Tian, G.; Walenga, R. Pharmaceutical aerosols deposition patterns from a Dry Powder Inhaler: Euler Lagrangian prediction and validation. Medical Engineering and Physics 2017, 42, 35-47. doi:10.1016/j.medengphy.2016.11.007.

20. Kopsch, T.; Murnane, D.; Symons, D. Computational modelling and experimental validation of drug entrainment in a dry powder inhaler. International Journal of Pharmaceutics 2018, 553, 37-46. doi:10.1016/j.ijpharm.2018.10.021.

21. Chalvatzaki, E.; Chatoutsidou, S.E.; Lazaridis, M. Simulations of the deposition of pharmaceutical aerosols in the human respiratory tract by dry powder inhalers (DPIs). Journal of Drug Delivery Science and Technology 2020, 59, 101915. doi:10.1016/J.JDDST.2020.101915.

22. Finlayson-Pitts, B.J.; Pitts, J.N. Analytical Methods and Typical Atmospheric Concentrations for Gases and Particles. Chemistry of the Upper and Lower Atmosphere 2000, pp. 547-656. doi:10.1016/B978-012257060-5/50013-7.

23. Kulkarni, V. Handbook of non-invasive drug delivery systems : science and technology; 2009.

24. Bonam, M.; Christopher, D.; Cipolla, D.; Donovan, B.; Goodwin, D.; Holmes, S.; Lyapustina, S.; Mitchell, J.; Nichols, S.; Pettersson, G.; Quale, C.; Rao, N.; Singh, D.; Tougas, T.; Oort, M.V.; Walther, B.; Wyka, B. Minimizing variability of cascade impaction measurements in inhalers and nebulizers. AAPS PharmSciTech 2008, 9, 404-413. doi:10.1208/S12249-008-9045-9/FIGURES/1.

25. Darquenne, C. Deposition Mechanisms. Journal of Aerosol Medicine and Pulmonary Drug Delivery 2020, 33, 181-185. doi:10.1089/jamp.2020.29029.cd.

26. Tsuda, A.; Henry, F.S.; Butler, J.P. Particle Transport and Deposition: Basic Physics of Particle Kinetics. Comprehensive Physiology 2013, pp. 1437-1471. doi:10.1002/cphy.c100085.

27. Tomasi, C.; Fuzzi, S.; Kochanovskij, A.A., Eds. Atmospheric aerosols: life cycles and effects on air quality and climate; Wiley series in atmospheric physics and remote sensing, Wiley-VCH Verlag GmbH \& Co. KGaA: Weinheim, 2017.

28. Borghardt, J.M.; Kloft, C.; Sharma, A. Inhaled Therapy in Respiratory Disease: The Complex Interplay of Pulmonary Kinetic Processes 2018. doi:10.1155/2018/2732017.

29. Chow, A.H.L.; Tong, H.H.Y.; Chattopadhyay, P.; Shekunov, B.Y. Particle Engineering for Pulmonary Drug Delivery. Pharmaceutical Research 2007, 24, 411-437. doi:10.1007/s11095-006-9174-3.

30. Boer, A.H.D.; Gjaltema, D.; Hagedoorn, P.; Frijlink, H.W. Characterization of inhalation aerosols: a critical evaluation of cascade impactor analysis and laser diffraction technique. International Journal of Pharmaceutics 2002, 249, 219-231. doi:10.1016/S03785173(02)00526-4.

31. Judge, E.P.; Hughes, J.M.L.; Egan, J.J.; Maguire, M.; Molloy, E.L.; O’Dea, S. Anatomy and Bronchoscopy of the Porcine Lung. A Model for Translational Respiratory Medicine. American Journal of Respiratory Cell and Molecular Biology 2014, 51, 334-343. doi:10.1165/rcmb.2013-0453TR.

32. Rogers, C.S.; Abraham, W.M.; Brogden, K.A.; Engelhardt, J.F.; Fisher, J.T.; McCray, P.B.; McLennan, G.; Meyerholz, D.K.; Namati, E.; Ostedgaard, L.S.; Prather, R.S.; Sabater, J.R.; Stoltz, D.A.; Zabner, J.; Welsh, M.J. The porcine lung as a potential model for cystic fibrosis. American Journal of Physiology-Lung Cellular and Molecular Physiology 2008, 295, L240-L263. doi:10.1152/ajplung.90203.2008.

33. Convention, U.S.P. USP35 NF30, 2012: <601> Aerosols, Nasal Sprays, Metered-Dose Inhalers, and Dry Powder Inhalers; The United States pharmacopeia, United States Pharmacopeial, 2011.

34. Pasteka, R.; Santos da Costa, J.P.; Barros, N.; Kolar, R.; Forjan, M. Patient-Ventilator Interaction Testing Using the Electromechanical Lung Simulator XPULM ${ }^{\mathrm{TM}}$ during V/A-C and PSV Ventilation Mode. Applied Sciences 2021, 11, 3745. doi:10.3390/app11093745.

35. Pasteka, R.; Forjan, M.; Sauermann, S.; Drauschke, A. Electro-mechanical Lung Simulator Using Polymer and Organic Human Lung Equivalents for Realistic Breathing Simulation. Scientific Reports 2019, 9, 19778.

36. Ahookhosh, K.; Pourmehran, O.; Aminfar, H.; Mohammadpourfard, M.; Sarafraz, M.M.; Hamishehkar, H. Development of human respiratory airway models: A review. European Journal of Pharmaceutical Sciences 2020, 145, 105233. doi:10.1016/J.EJPS.2020.105233.

37. Russell, W.M.S.; Burch, R.L. The principles of humane experimental technique; Methuen London, 1959; p. 238 p.

38. Horváth, A.; Balásházy, I.; Tomisa, G.; Farkas, Á. Significance of breath-hold time in dry powder aerosol drug therapy of COPD patients. European Journal of Pharmaceutical Sciences 2017, 104, 145-149. doi:10.1016/j.ejps.2017.03.047.

39. Buttini, F.; Brambilla, G.; Copelli, D.; Sisti, V.; Balducci, A.G.; Bettini, R.; Pasquali, I. Effect of Flow Rate on In Vitro Aerodynamic Performance of NEXThaler ${ }^{\circledR}$ in Comparison with Diskus ${ }^{\circledR}$ and Turbohaler ${ }^{\circledR}$ Dry Powder Inhalers. Journal of Aerosol Medicine and Pulmonary Drug Delivery 2016, 29, 167-178. doi:10.1089/jamp.2015.1220.

40. Sahin-Yilmaz, A.; Naclerio, R.M. Anatomy and physiology of the upper airway. Proceedings of the American Thoracic Society 2011, 8, 31-39. doi:10.1513/pats.201007-050RN.

41. Thomas, R.J. Particle size and pathogenicity in the respiratory tract. Virulence 2013, 4, 847-858. doi:10.4161/viru.27172.

42. Lippmann, M.; Yeates, D.B.; Albert, R.E. Deposition, retention, and clearance of inhaled particles. British Journal of Industrial Medicine 1980, 37, 337-362. doi:10.1136/oem.37.4.337.

43. Darquenne, C. Aerosol deposition in health and disease. Journal of Aerosol Medicine and Pulmonary Drug Delivery 2012, $25,140-147$. doi:10.1089/jamp.2011.0916. 
44. Usmani, O.S.; Biddiscombe, M.F.; Nightingale, J.A.; Underwood, S.R.; Barnes, P.J. Effects of bronchodilator particle size in asthmatic patients using monodisperse aerosols. Journal of applied physiology (Bethesda, Md. : 1985) 2003, 95, $2106-2112$. doi:10.1152/JAPPLPHYSIOL.00525.2003.

45. Usmani, O.S.; Biddiscombe, M.F.; Barnes, P.J. Regional lung deposition and bronchodilator response as a function of $\beta 2$-agonist particle size. American Journal of Respiratory and Critical Care Medicine 2005, 172, 1497-1504. doi:10.1164/rccm.200410-1414OC.

46. Newman, S.; Malik, S.; Hirst, P.; Pitcairn, G.; Heide, A.; Pabst, J.; Dinkelaker, A.; Fleischer, W. Lung deposition of salbutamol in healthy human subjects from the MAGhaler dry powder inhaler. Respiratory Medicine 2002, 96, $1026-1032$. doi:10.1053/rmed.2002.1387.

47. Virchow, J.C.; Poli, G.; Herpich, C.; Kietzig, C.; Ehlich, H.; Braeutigam, D.; Sommerer, K.; Häussermann, S.; Mariotti, F. Lung Deposition of the Dry Powder Fixed Combination Beclometasone Dipropionate Plus Formoterol Fumarate Using NEXThaler® Device in Healthy Subjects, Asthmatic Patients, and COPD Patients. Journal of Aerosol Medicine and Pulmonary Drug Delivery 2018, 31, 269-280. doi:10.1089/jamp.2016.1359.

48. Levy, M.L.; Carroll, W.; Izquierdo Alonso, J.L.; Keller, C.; Lavorini, F.; Lehtimäki, L. Understanding Dry Powder Inhalers: Key Technical and Patient Preference Attributes. Advances in Therapy 2019, 36, 2547-2557. doi:10.1007/s12325-019-01066-6.

49. Newman, S.P.; Busse, W.W. REVIEW: Evolution of dry powder inhaler design, formulation, and performance. Respiratory Medicine 2002. doi:10.1053/rmed.2001.1276.

50. Abadelah, M.; Abdalla, G.; Chrystyn, H.; Larhrib, H. Gaining an insight into the importance of each inhalation manoeuvre parameter using altered patients' inhalation profiles. Journal of Drug Delivery Science and Technology 2021, 61, 102181. doi:10.1016/j.jddst.2020.102181.

51. Hira, D.; Okuda, T.; Mizutani, A.; Tomida, N.; Okamoto, H. In Vitro Evaluation of Optimal Inhalation Flow Patterns for Commercial Dry Powder Inhalers and Pressurized Metered Dose Inhalers With Human Inhalation Flow Pattern Simulator. Journal of Pharmaceutical Sciences 2018, 107, 1731-1735. doi:10.1016/j.xphs.2018.02.002.

52. Wei, X.; Hindle, M.; Kaviratna, A.; Huynh, B.K.; Delvadia, R.R.; Sandell, D.; Byron, P.R. In vitro tests for aerosol deposition. VI: Realistic testing with different mouth-throat models and in vitro - In vivo correlations for a dry powder inhaler, metered dose inhaler, and soft mist inhaler. Journal of Aerosol Medicine and Pulmonary Drug Delivery 2018, 31, 358-371. doi:10.1089/jamp.2018.1454.

53. Hamilton, M.; Leggett, R.; Pang, C.; Charles, S.; Gillett, B.; Prime, D. In vitro dosing performance of the ELLIPTA® dry powder inhaler using asthma and COPD patient inhalation profiles replicated with the electronic lung (eLung ${ }^{\mathrm{TM}}$ ). Journal of Aerosol Medicine and Pulmonary Drug Delivery 2015, 28, 498-506. doi:10.1089/jamp.2015.1225. 